\title{
What Graduate Students from Diverse Disciplines Learn about Teaching from Working with Middle School Teachers and Students
}

\author{
Christopher Marc Roemmele ${ }^{1}$, Jon Harbor ${ }^{1} \&$ Daniel Nelson Moore ${ }^{1}$ \\ ${ }^{1}$ Purdue University, West Lafayette, IN, USA \\ Correspondence: Christopher Marc Roemmele, GK-12 Program Coordinator, PhD Candidate in Geoscience \\ Education, Earth, Atmospheric \& Planetary Sciences Department, Purdue University, West Lafayette, IN, USA.
}

Received: February 14, 2017

Accepted: March 9, 2017

Online Published: March 10, 2017

doi:10.5430/irhe.v2n1p79

URL: https://doi.org/10.5430/irhe.v2n1p79

\begin{abstract}
We investigated how a program (GK-12) that engages diverse graduate students with middle school teachers and children impacts the participants' teaching knowledge over a period of one day a week over ten-weeks. The experience includes graduate students developing and delivering a standards-based, hands-on and inquiry-infused lesson centered around their research interests. Qualitative analysis of reflective journals of the participants show that this intensive engagement with teachers and students increased their understanding and experience with pedagogical techniques and strategies to promote and improve student learning and understanding, developing and enhancing personality traits that encourage a positive culture for learning, and acquiring strategies and the fortitude needed to meet and deal with multiple priorities in a complex teaching environment. These results suggest that GK-12 type programs provide graduate students with skills and experiences that can be valuable when seeking employment in industry, the public or nonprofit sector, or as faculty at post-secondary institutions. Continued research of the program is necessary to determine how past participants have utilized these skills as a competitive advantage in their careers.
\end{abstract}

Keywords: GK-12, graduate student, K-12 education, pedagogy, outreach

\section{Introduction}

"Along with excellent research skills, employers seek skills in communication, teamwork, interpersonal relationships, administration, and leadership. Other in-demand skills include networking, creativity, initiative, mentorship, and maintaining life balance." (Lee and Reithmeier, 2013).

Over 50,000 new doctorates are earned each year in the US (National Science Foundation, 2015), and the primary purposes of completing many graduate-level degree programs include acquiring advanced content knowledge and skills, as well as developing and honing research skills through completion of a project in the candidate's field of interest. Upon completing their degrees, these highly-qualified individuals then typically seek positions either as faculty members or in private business and industry, public (government) service, and the non-profit sector, although proportions vary depending on the academic discipline the doctoral degree was achieved in (Wendler et al, 2012). Most graduate students seeking faculty positions in higher education are expected to have completed a significant research project, such as a dissertation or thesis (Page, Wilhelm, \& Regens, 2011), and graduate programs are typically well-designed to help students achieve this goal. However, the vast majority of faculty positions in the US are in institutions with a primary mission of instruction, and research-intensive universities also expect potential faculty to teach both introductory and upper-level courses to undergraduate and graduate students. Regional universities, liberal arts colleges, community colleges, tribal colleges and universities, and two-year colleges often place greater emphasis on the instructional experience and interests of applicants than on fine distinctions in the quality and impact of an applicant's research results. Yet only recently have graduate programs outside of Colleges of Education started to provide systematic opportunities and encouragement for graduate students to acquire advanced knowledge and experience in pedagogy (Huziak-Clark et al, 2006; Van Hook et al, 2009). For example, some graduate schools have initiated an advanced graduate teaching certificate, which requires teaching assistants to develop and improve their instructional abilities.

Graduate students who seek positions in business, industry, or government service are hired on the basis of the focus and quality of their research skills, but also on other attributes such as their ability to communicate to a wide range of 
stakeholders, investors, and potential clients. Many employers evaluate candidates on their communication skills, their potential to develop as mentors, trainers, and managers, and their willingness to help build internal and external community, including through corporate outreach and community relations. As with higher-education pedagogy, only recently have graduate programs started to provide systematic opportunities and encouragement for graduate students to acquire advanced knowledge and experience in mentoring, community outreach, and communicating with diverse audiences (all of which are pedagogical skills). This issue of employability is certainly within the scope of graduate programs goals. However, the focus of our research is more narrowly confined to the objectives of a specific program and the enduring knowledge and skills of teaching and learning that participants take from this program.

From 1999 to 2009, the National Science Foundation funded over 200 "GK-12" programs at colleges and universities to connect selected graduate students ("G") with teachers and children ("K-12") in intensive programs designed to evaluate the impacts of such interactions on graduate students (Cormas \& Barufaldi, 2011). The research from these programs showed that participating graduate students (called GK-12 Fellows) in Science, Technology, Engineering, and Mathematics (STEM) fields improved in a number of skills that included teaching and research ability, communication across different media and audiences, as well as working in collaborative environments, all of which are fundamental for future faculty and other professional positions (Page et al, 2011; Mitchell et al, 2003; McBride, 2011; Cormas \& Barufaldi, 2011). This prior body of research has evaluated the strength and value of the program to the graduate students in terms of the acquisition of skills. But the GK-12 program places these graduate students in classrooms to teach and develop lessons, and the professional and personal skills and traits of teachers and teaching have not been systematically evaluated in prior research.

GK-12 programs have also had impacts on cooperating teachers, including strengthening their content knowledge and their pedagogical strategies (especially inquiry-based approaches). The K-12 students involved in GK-12 programs were exposed to new role models and innovative lessons that the GK-12 fellows developed that may not otherwise have been available in a typical classroom setting (Avery et al, 2003; Huziak-Clark et al, 2006; Van Hook et al, 2009; Thompson et al, 2002). Although these are substantial contributions to the GK-12 community, investigation into specific gains in the understanding that fellows have about the practice of teaching and the challenges which surround a classroom teacher have not been evaluated in detail. In addition, the National Science Foundation and the universities and colleges that received grants intended for these projects to be sustained after the period of grant funding, because of the significant positive impacts on graduate students and K-12 partners, but such sustained programs are rare and there has been little research on the impacts that they have (Weeks \& Harbor, 2014; Weeks et al, 2015). In particular, there is a lack of research into the role of the fellow in sustained programs, and the changing lens by which they view the teaching profession.

GK-12 fellows have some commonalities with student teachers who are in the classroom as part of a teacher education degree program. The expectation is that student teachers will learn about various components of the practice and art of teaching and the different ways children can learn. Additionally, student teachers gain knowledge and experience in lesson planning, maintaining classroom discipline, and fostering relationships with their students, colleagues, administrators and parents (Ferry, 2010). However, student teachers take part in this endeavor because being a practicing secondary or elementary teacher is their immediate career goal. The immediate career goals of GK-12 fellows are rarely to become a K-12 teacher, and GK-12 fellows may not have had any notable or relevant teaching experience prior to their involvement in the program. Although some may have held positions as a teaching assistant for a laboratory or in a classroom as a graduate or undergraduate student, typically there has been little in-depth pedagogical training associated with these positions. The structure of a GK-12 program also requires far fewer classroom hours than student teaching, where daily attendance for a semester is required. Despite differences in time commitments, backgrounds, and career paths, GK-12 fellows can potentially gain learning outcomes that rival those of student teaching programs. Prior research into GK-12 programs has provided strong evidence forgains in some GK-12 fellows' skills and knowledge in teaching to diverse audiences, communicating research to students, and developing student-centered inquiry-based teaching strategies (Weeks \& Harbor, 2014; Trautman \& Krasny, 2006) which overlap with both the goals of these GK-12 programs and the goals of graduate programs in general (Weeks, Gong, \& Harbor, 2015; Laursen, Thiry, \& Liston, 2012). However, they do not address the changing outlook of participants on the role of the teacher and how they personalize this experience, and potentially move forward armed with this new perspective on the teaching and teachers.

Thus, research on GK-12 programs reveals that graduate students can benefit because the program provides a teaching experience that impacts learning outcomes not strictly related to teaching, such as time management and general communications skills, as well as job marketability. However, related studies indicate that a program such as 
GK-12 should provide experiences that allow fellows to define, develop, and refine the skills to become a teacher in their own right by learning from their cooperating teacher and the students they teach. These takeaways are important; teaching at the K-12 level is as demanding and time-intensive, if not more, as university level instruction. It is this developmental aspect which has not been studied intensively in prior research of original NSF-funded GK-12 programs or current sustained programs. It is this construct that forms the objective of this study.

\section{GK-12 Program Overview}

The specific GK-12 program that is the focus of the research reported here is a locally sustained program at a large Midwestern, research-intensive, land-grant university.that places graduate students from all disciplines (not only STEM) in middle school classrooms for one day a week for ten weeks. Originally funded by the National Science Foundation, the goals of the program are to develop pedagogical knowledge and skills, improve communication with younger and diverse audiences, and establish a base for future educational and engagement experiences as professionals and faculty. Although the original NSF structure provided graduate assistantships for participants, the sustained GK-12 is now a program that graduate students can elect to participate in as volunteers or for graduate credit. Many of the participants are recruited through presentations given within Preparing Future Faculty and Preparing Future Professional classes offered by the graduate school at the university, as these students have already taken action to acquire additional knowledge and skills focused on their future careers.

This sustained GK-12 program is organized to provide participants (called GK-12 fellows) with a scaffolded teaching experience. Fellows receive some initial training and then spend their first two weeks observing the teacher and classroom. They then progress to co-teaching lessons with the teacher they are collaborating with, and have regular discussions and additional training sessions with the program staff. During the middle and later stages of the program, fellows develop an original lesson to be taught in their classroom, based on aspects of their graduate research and using various pedagogical strategies, including inquiry, hands-on and discovery learning. Additionally, the lesson is required to meet state and national standards. The GK-12 program includes training and workshops that provides fellows with the tools and experience to apply different aspects of pedagogy including lesson planning, learning objectives, and understanding the realities of middle school learners and middle school itself. Because the program is locally sustained through the university, fellows practice grant-writing by applying for service learning grants in order to obtain supplies for their lessons. By the end of their 10 weeks in the classroom, each fellow implements their lesson in their classroom over the course of 1-3 days. Further details of the program are provided in Weeks \& Harbor (2014).

Even though fellows do not intend to become middle or secondary school teachers, many anticipate becoming faculty at the university level, or using the skills and experience they gain as part of private or public sector positions. Regardless of their individual goals, possessing the skills to communicate their expertise and knowledge to all stakeholders is an important part of fellows' future careers aspirations. Spending time with an experienced teacher, and a cohort of students throughout the length of the program can provide fellows with a new lens through which to view their own professional pursuits (McBride et al, 2011; Page et al, 2011).

\section{Purpose and Research Questions}

The purpose of this qualitative study is to explore the pedagogical learning that takes place as a result of interactions between teachers, K-12 students, and participants in a sustained GK- 12 program at a large Midwestern, research-intensive university. Improved pedagogical knowledge and practice are goals of the program, thus it is important to see what components of these are being met and how these goals are being achieved. The main research question is: What do fellows learn about teaching, learning, and education in general from their cooperating teachers and the students they teach? The findings of such research can both inform future changes in the existing program being studied here, as well as provide insight for the development of programs at other colleges and universities that are seeking to achieve expanded learning outcomes for graduate students. A longitudinal study of past participants to determine the impact of the GK-12 program on their professional careers and marketability can also provide for changes to the program in order to best suit the needs of future professionals and faculty.

\section{Research Methods}

\subsection{Framework}

Our research is guided by the framework of phenomenology. The goal of our phenomenological approach is to shed light on the specific experiences of the fellows as they are perceived by the fellows themselves, and as they emerge from fellows' observations in written narrative journals that were completed throughout the program. Investigating life events (in this case the GK-12 program experience) and the meanings these events have for the participants 
(Creswell, 2007; Merriam, 2002) is the essence of this paradigm. This is done within a framework that places the experiences that emerge from the fellows' journals in the context of overarching goals identified by the program designers. By analyzing the fellows' journals we seek to identify the relevance and importance of participants changing views and understanding of teaching and learning.

\subsection{Participants and Data Sources}

GK-12 fellows were graduate students and post-doctoral students who chose to be a part of the program for one semester. These participants included both men and women, domestic and international students, with majors across the academic spectrum. A total of 60 participants were included in this study. These participants spanned 10 semesters of ongoing program, starting with the cohort of fellows in the spring of 2010 through spring of 2015. Although the sample of fellows is self-selected, fellows come from such diverse backgrounds, disciplines, and limited teaching experience and knowledge about the K-12 education system. Thus, the value in their opinions and lens through which they see and change the way they view teaching and learning is valid to report.

Program requirements included completing a journal reflection each week for the 10 weeks of the program. The fellows were given writing prompts and questions to help them reflect upon their experiences in the classroom. The prompts and questions changed systematically as fellows went from observing to co-teaching to teaching their lesson. A variety of topics were included in the prompts including making observations about the teacher and teaching, the students, and lesson planning. The journals allowed GK-12 staff to provide guidance and feedback about fellows' experiences and progress, and to adjust and refocus training meetings to address their concerns. Since the data sources were a required part of the program, the study complies with the university's human subject research requirements.

\subsection{Data Analysis}

Data analysis was performed using open coding. Prior to reading the first journals, authors first established a priori themes that they believed would emerge, based on prior knowledge of the program and teaching experience. Then authors read through each journal separately, identifying pre-determined themes and finding new emergent themes in the phrases, sentences, and paragraphs that the fellows wrote. Authors then met to discuss the theme coding and establish reliability in the coding system. This was done by identifying the theme and where it occurred within the participants' journals and finalizing agreement between the authors. If the authors differed on code placement within a particular journal entry, they discussed differences and revised themes until consensus was achieved. Each theme was also defined operationally so that the authors understood and were clear on the various meanings that a particular code could have. Axial coding was then performed by the authors, as related codes were grouped and consolidated into overarching primary, secondary and tertiary themes The codes were counted and the number of participants in whose journals the codes were identified were also determined (see Table 1).

Table 1. Themes emerging from journals of participants in a sustained GK-12 program

\begin{tabular}{|c|c|c|c|c|}
\hline Themes & Secondary Themes & Tertiary Themes & $\begin{array}{l}\text { Prevalence } \\
(1.00=60)\end{array}$ & Counts \\
\hline \multirow[t]{4}{*}{ Pedagogy } & Process and Art of Teaching & & $\underline{0.92}$ & 238 \\
\hline & Flexibility & & $\overline{0.70}$ & 140 \\
\hline & Knowing Your Audience & & 0.80 & 149 \\
\hline & Pedagogical Differences & & 0.12 & 8 \\
\hline \multirow[t]{6}{*}{ Hard Work } & Preparation & & 0.45 & 80 \\
\hline & Rewards & & 0.18 & 25 \\
\hline & Challenges & General & 0.63 & 93 \\
\hline & & $\begin{array}{l}\text { Cultural } \\
\text { Differences }\end{array}$ & 0.12 & 23 \\
\hline & & $\begin{array}{l}\text { Outside } \\
\text { Influences }\end{array}$ & 0.33 & 41 \\
\hline & & Misconceptions & 0.20 & 23 \\
\hline \multirow[t]{3}{*}{ Environment } & $\begin{array}{l}\text { CEEEP } \\
\text { (Compassion-Empathy-Energy-Enthusiasm-Patience) }\end{array}$ & & 0.55 & 81 \\
\hline & Classroom Management & & 0.83 & 167 \\
\hline & Relationships & & 0.73 & 140 \\
\hline
\end{tabular}




\section{Results and Discussion}

The findings from this study reveal that there were three distinct themes, all of which are further broken down into several secondary themes. The primary themes that emerged from the journal entries are: 1) Pedagogy, 2) Teaching is Hard Work, and 3) Classroom Environment. See Table 1 for the frequency of counts of these themes and the secondary themes. Each theme and secondary theme is operationally defined below. Quotes from participant journals are given as exemplars.

\section{Primary Theme 1: GK-12 fellows learn pedagogical skills from their cooperating teachers, and their students.}

The fellows discussed the influence of their cooperating teacher on what they learned in the classroom. The multi-modal forms of instructional techniques, the format and delivery of the lesson, and the skill by which this was achieved were all noted by nearly every GK-12 participant throughout all phases of the program, and regardless of subject discipline. This theme consisted of several secondary themes.

\section{Secondary Theme: The Practice and Art of Teaching}

Teaching can be viewed as a profession needing definite training and skills, and the GK-12 fellows recognized this. Teaching is also arguably an art, because although teachers need the knowledge, skills, and understanding of procedures, a great deal of individual expression, creativity, and improvisation takes place. Since one of the goals of the GK-12 program is to learn about and improve their pedagogical skills, the number of participants who cited this and the number of times this code appeared was the highest $(0.92,238)$.

Participants saw that guided inquiry and scaffolding are effective tools:

"It is better to let students figure out problems by themselves...I wouldn't tell them answers directly...ask them what they think is right... and ask them constructive questions to help them think," and, "I need to try to guide them through things without just telling them."

The fellows also realized that the 45 -minute class time is often chunked into different learning components and, for the benefit of the students, never just constant lecture.

“Activity, activity, activity: the teacher's movement or tasks for the students," and, "I realized how important a good activity can be because that can really help them understand what they are learning about," and, "Keeping students constantly engaged and interested throughout the lesson is necessary."

Watching their cooperating teachers employ a plethora of skills that made learning meaningful and relevant, and allow for differentiated learning, reminded the fellows how they needed to craft their own teaching: "I need an interactive skill with the students...I will give...questions to attract their interests in the next lesson," and, "I learned that I need to try to make connections with the material and subjects and experiences they are already familiar with," and, "I saw students are strongly interested in doing the research (the teacher assigned)...chosen by themselves, and they are very creative with it."

Participants noted that teaching is much more than walking into a lecture hall or classroom and reading from a book, board, or screen:

"I learned there is a craft to being a good teacher...it takes great skill to be able to effectively make use of the knowledge one may have," and "Teaching is an interaction between the teacher and the students, it isn't just putting knowledge into their heads."

This was the most common recurring subtheme throughout the journals. Exposure to and practicing a variety of teaching styles and strategies corresponds to one of the goals of the sustained GK-12 program.

\section{Secondary Theme: Flexibility}

GK-12 fellows quickly realize that teaching often requires on-the-go and on-your-feet decision making. These decisions often impact the structure and delivery of the lesson via modifying, adapting, and improvising in order to accommodate the needs of the many types of learners encountered in different classes throughout the day.

"Each lesson has to be tuned to the abilities of each class," and "Good teaching means being creative in your approach to reaching all students...they come with different learning styles, deficiencies and interests."

GK-12 fellows were cognizant of the rapid changes that sometimes took place when there seemed to be difficulty or resistance to understanding the concept or activity. At the same time, fellows came to understand that teachers needed to allow students flexibility to proceed at different paces. 
"Effective teachers... able to change the lesson plan according to the learning of the students," and, "Due to varying ability levels... used different types of interaction...she was flexible and respected student choices regarding which activity to do based on their own ability and interest," and, "I learned I need to be flexible... and to have a second option to implement because unexpected events happen or students call attention to other things," and, "Teaching means...to adapt teaching techniques that are not working on the fly."

Although lesson plans are exactly that, a detailed plan of the objectives activities that will occur, fellows learned that they are organic and constantly evolving and being revised as the lesson progresses by a teacher whose has the best interest of the students in mind. Fellows learned that good teaching requires flexibility, and swift and sure decision-making due to the ever-changing nature of a "typical" school day.

\section{Secondary Theme: Knowing Your Audience}

Fellows who spent days observing and co-teaching in the classroom became aware that their cooperating teachers were constantly changing the way they taught the same lesson on the same day. Teachers at the participating middle school taught six periods a day, yet because the individual teacher understood the dynamics of each period, the structure and flow of the lesson was different each time. Knowing the makeup of each class - the intellectual ability, emotional maturity and needs, and the idiosyncratic personalities - and the subsequent adjustment and adaptation of the lesson to allow for those not-so-subtle differences - is an aspect of teaching that fellows may not previously been aware of and often differs considerably from their recent undergraduate or graduate school experiences.

"You need to know your students well and be aware of...reactions and needs in class...differentiated teaching is necessary," and, 'Effective teachers adjust lessons based on their students... with different styles of teaching because...kids will react differently."

Specific student characteristics were also a trait that teachers knew about their students and that fellows perceived as an influence to learning.

"I realized...by knowing learners' confidence it has significant impact on their learning," and, "She does an excellent job of catering to all...she gives notes, they read, some do different activities for all learning types."

Fellows learned that their teachers provided certain types of learning activities because of their familiarity with their students' abilities and needs in order to better understand the concepts being taught. This idea became more pervasive as fellows progressed through the co-teaching and teaching phases of the program.

"I need to pick and choose better...to explain the topics and definitions and concepts...to adjust to students' levels," and, "Relate lessons to things they already know, but don't dumb it down so that you insult their intelligence," and, "It was helpful...to include game-like activities...because it helps students to relax and learn better."

The GK-12 fellows were in classrooms that were quite diverse in terms of race and ethnic background, socioeconomic status, intellectual capabilities and personalities (both individually and as a group). Learning to be knowledgeable of student backgrounds and adaptive for these characteristics was a significant part of the daily functions of a classroom teacher that enhanced the learning and learning environment.

\section{Secondary Theme: Pedagogical Differences}

Although many GK-12 fellows had no prior classroom teaching experience, they were perceptive and become concerned about the most effective learning approaches for the students they worked with. Fellows were quick to learn aspects of pedagogy from the program training and their cooperating teachers, so they question certain decisions that teachers make about the execution of a lesson, and wonder why and how those decisions were made, sometimes injecting their own solution to the situation. Comments about these differences ranged from mild concern:

"We have different methods of explaining things because of our different backgrounds," and "Teachers asked yes and no questions and did not leave students enough space and time to ask questions, which is not nurturing active exploration."

To much more strong disagreement with what their teacher did in a particular situation:

"She handed out the invitations as I was beginning...the class had difficulties paying attention, she should have waited until the end," and, "I saw a student copying the answers for a worksheet... when I approached (the teacher), he said at least they are putting in effort. I struggled with this a lot..."

Or in their teacher's general style of teaching:

"Lecture, lecture, lecture. I am an adult... and I am bored. She has them read the book because she doesn't think they can do homework. I don't think she is doing them any favors, high school and college teachers will not be kind, "and, 
"He has informal interactions...to the point where...it is detrimental...the students don't do the assignments... because there aren't any consequences."

Classroom teaching demands constant attention and awareness of a variety of situations and activities, some not always directly related to learning. Although difficult to put oneself into the same shoes as the classroom teacher at the time, GK-12 fellows were observant throughout their experiences to confirm and express what they felt was inefficient or unsatisfactory execution of a lesson or classroom management skills, and how these occurrences may have been better resolved. The rarity of this code and number of fellows who discussed this in their journals $(0.12,8)$ is very low for the sample, which may indicate that most fellows felt comfortable with the pedagogical and classroom management choices their cooperating teachers were making.

\section{Primary Theme 2: Teaching is Hard Work}

GK-12 fellows swiftly learn that teaching is a hard job, and much harder than they originally imagined. While the school day starts at 8:00am and ends at 3:15pm, fellows grasp that the teaching "day" starts before any students enter their classrooms and ends well after the last student has left the building. Although this is emphasized in training, the participants are suddenly involved in the lives of their cooperating teacher and their own lesson planning. They come to the realization that there is work to be done during the school day during prep periods, after school, in the evenings, and weekends: meetings, answering emails, phone calls, grading, printing, extra help, and advising clubs. This is in addition to lesson planning, instruction, and reflecting on what has worked well for the students and for the teacher as the basis for modifying upcoming instruction. There is accountability in testing, new tests, new standards and new curriculum. Issues of class size, budget cuts, students from many ethnicities and socioeconomic and academic levels and needs across the spectrum all are of concern throughout the course of a workweek. As one fellow succinctly put it, "I find myself surprised by the number of roles the teacher needs to play."

\section{Secondary Theme: Preparation}

New teachers and pre-service teachers are often told, "You are planning to fail if you fail to plan." Although instruction is often seen as the primary and most visible aspect of a teacher's job, getting and being prepared occupies a good deal of physical and emotional time. Lesson planning, setting up materials for activities, creating slideshows and tests must all be done with careful thought ahead of time. Without this dedicated effort, there is the possibility of unfortunate consequences in student performance or behavior if this is handled too cavalierly.

This was expressed succinctly by one fellow, "Plans are critical," and often came with suggestions based on their observations, "In order for the lesson to go smoothly, a teacher truly has to be prepared...and anticipate questions that go outside the realm of your specific lesson... be prepared to answer them right away or...follow-up questions the next day," and,

"This made me realize that...it's important...to plan time either before or after the activity to go over the main concepts the students should be picking up." One fellow suggested an even more rigid route in planning, "Set up time scientifically."

Quality time spent on lesson planning did change the outcome of the lesson, "When she is prepared, the lesson runs more smoothly and she is able to command their attention more."

Fellows realized how their own capabilities and outlook on the effect of planning would impact their teaching,

"I am not someone that can just jump into teaching any topic... without clear knowledge of,,,the goals...it is harder for me to have confidence in getting the lesson across," and, "It changed my understanding of how much work it takes to get a lesson together and execute it."

GK-12 fellows learned that there is no substitute for being prepared when it comes to teaching students. Regardless of the lesson, topic, activity or specific class, fellows saw their cooperating teachers be proactive in their execution of lesson, and understood that "winging it" is not an acceptable alternative when it comes to teaching students of any age.

\section{Secondary Theme: Challenges}

The time fellows spent at the school and in the classroom allowed for the realization that teaching every day and trying to meet the needs of all students, given all the variables that go into a "typical" school day, is a challenging task, even for the best of teachers. There are a number of situations and obstacles that serve as either a distraction, a roadblock, or both. Yet, the cooperating teachers showed resiliency and fortitude to ensure that teaching and learning take place, although with varying amounts of success. Fellows expressed this rather explicitly. 
"The awareness of time...is somewhat a detriment to learning, because it was clear at some times where students might have benefitted from a little more time to discuss a topic. The full lesson was never actually completed... which means the cohesiveness of the concepts was partially lost on the students...because there wasn't enough time," and, "Students having varying ability levels...is challenging for the teacher to attend to every student's needs, but the teachers has to ensure that ...needs are met...being a...teacher is not easy," and, "It is the teacher's responsibility to teach students no matter who they are, how often they go to school... has to do all he could to help students achieve... although that is pretty challenging."

\section{Tertiary Theme: Greater Issues}

Fellows were continually exposed to the realities of high-stakes testing and how that impacted the daily lives of the teachers and the students.

"I learned there is a disconnect between state education requirements and the classroom," and, "they were concerned about (the state test) that students need to be prepared for...too much time spending (on) group work and modeling activities that might not help students for (the state test)."

It was equally surprising to participants how what might have seemed like small factors, such as fire drills, snow delays, assemblies, or simply the day of the week (especially Monday and Friday), made an impact on the lesson plan and on the emotions and behavior of the students. Still deeper and perhaps more difficult to overcome are those constructs of socioeconomic backgrounds, parental indifference, general student apathy and distrust toward education. Teaching middle school students in heterogeneous classes was bought up by the fellows.

"...more effective to have a curriculum that is different for students in various levels...students finish their activities quickly and have to wait for other students...could be long and boring...on the other hand, equal opportunities are given, some students just do not want to pay attention and have to be given step-by-step instructions...I am not sure if they are learning anything," and in a stronger but similar vein, "I really don't think it can get more simple than reading and finding your description of a picture...these kids are so behind and...I think teachers are catering to the ones that are left behind, but what about the ones that care and are doing well? They just sit and read, the material is too simple...we should be pushing the students to learn more and do more than "dumb down" exercises even more...I'm just really disappointed."

Striking a balance between accountability and social progression was also a tough issue for fellows to reconcile.

“...strikes me as strange that even if students fail 8th grade...they still automatically progress to 9th grade...so that is quite interesting," and, “...many students do not have the required knowledge for their grade level even in the regular class...supposed to master by 6th grade...this makes teaching higher level knowledge very hard...it is a burden for the teacher to cover things that the student should know before, yet... has no choice...this wildly exists but there is no perfect solution."

The execution of long term projects and limited funds for supplies and lack of materials at home for a number of students became a concern for one fellow.

"all the classes have to share all the materials...groups can't create their projects until the final day, and they have to disassemble the projects...students were not happy...they don't like that they can't start their projects and the teacher doesn't like it but there is nothing she can do, she can't buy more materials..."

Due to the number of outside influences, and the contradictions and unexpected changes that they may result in, and their influence on the teaching and assessment format, GK-12 fellows found that these situations that were far beyond their control were sometimes frustrating and raised more questions than they answered. Teaching is not predictable nor controllable, and it is incredibly complex with numerous variables that affect students individually and as a class.

\section{Tertiary Theme 2: Cultural Differences}

A number of the GK-12 fellows were educated in countries other than the United States, and reflected on differences between their experiences as children and what they observed in an American school, in particular focused on the interaction between teacher and students, the teaching style of many American born and educated teachers, and student behavior in the classroom. What some of these fellows saw often contrasted sharply with their own experiences as a middle-school student in the country in which they were educated and they expressed a range of emotions about this usually in their first and second journals $(0.12,23)$

"...American students have different personalities in comparison...they express their ideas and feelings without embarrassment, they stand up in the classroom to look for calculators and materials...their look is more liberal." 
Despite this, American and students from this participant's homeland, “...share common characteristics such as they feel happy when they get a right answer, they like supportive feedback, simple things."

Fellows also identified positive aspects of American classrooms and their less formal climate. “...students discussed with each other on their assignment and (the teacher) crouched down to help those who had questions...," and that students in her country, "sit straight, arms on table, listen ... and keep silence...rarely raise hands to ask or answer questions and the teachers talk and write during the whole class." This fellow weighed both traditions and that there were positives and negatives to both, and that if she had to send her own child to one or the other, she hesitated to say which one. However, one teacher behavior struck several fellows, both international and domestic, as necessary trait that they needed to become comfortable with in doing in the classroom, "I need to lower my body when I help students in order to show that I am eager to help and that I am approachable."

\section{Tertiary Theme 3: Misconceptions}

GK-12 fellows encountered a full range of teacher styles, students, and activities. Regardless of where the fellow went through primary and secondary school, there were a variety of academic and non-academic situations that may have caught the fellow by surprise or changed their opinion about a particular aspect of teaching and learning, and of the students themselves.

Fellows realized that many students in the classes they were observing and teachers were not replicas of themselves as middle school students when it came to productivity and motivation.

“...it just made me realize how behind these kids are...they can't do fractions...I understand not understanding negative numbers...but 7 th graders should know fractions," and

"teachers met... and discussed the students' overall inability to write... a coherent one-page essay. I was writing (multiple) page essays..." and, "They read an essay and answered questions about it...the teacher went over the answers in class...I got to grade the work...I was thinking they would all get 100...there were a surprising amount of kids that didn't answer correctly, failed it, or got it completely wrong...I learned that teachers understand that some kids...just flat don't care."

The experience of working with students and seeing what difficulties they had with certain concepts was informative for their future research.

"But a lot of students had a hard time figuring out...the width and the length of the rectangle. I would have had no idea of this learning difficulty had I not seen it in the classroom because...it is common sense to me...it occurred to me that teachers take time and experience to know and predict what difficulties...students might have."

But participants' views on what the teaching profession encompassed also evolved.

"Before this, I thought teaching was merely just...delivering knowledge to students; now I believe teaching...is nurturing students through process, developing their interests and talents, and making them ready to explore their lives in the world."

The misconceptions that were realized by the fellows can fall into the realities of teaching and learning. Teachers need to be well-versed in their content areas, but their pedagogical knowledge skills extend to developmental psychology, classroom management, curriculum development, mentoring, and budgeting, among others. Student learning proceeds at a much different level and pace that what fellows recollect from their own experiences as a student.

\section{Secondary Theme: Rewards}

While teaching has its share of disappointments and heartache, there are moments and situations that are uplifting and inspiring that therefore validate why one may have chosen the profession. There may be comments, gestures, facial expressions, an answer on a test or assignment, during class or an extracurricular event that provides a sense of satisfaction, contentment and personal affirmation with teaching as a career. It may be dramatic or subtle, and students may have no idea of what is taking place, but they are what make the decision to become a teacher greatly worthwhile.

"I'm so glad to see students smiling faces once I answered their questions."

“...that adrenaline rush...when you walk by a group and the students are saying really astute things to each other that prove they have been paying attention and are engaged in what they are learning."

"I love my interaction with the students... and being positive role model to them." 
"It is rewarding when you see that students were really thinking about and reflecting upon what they have learned."

Despite their limited classroom time compared to their cooperating teachers, fellows still were able to get a sense of the overwhelming satisfaction and joy that comes with their interaction with students. For some, there was a realization that that teaching is much more than a job or a means to an end but rather a true vocation. The fellows got to see and experience the fruits of their efforts and time spent.

\section{Primary Theme 3: Classroom Environment}

By environment, we include the classroom climate and feeling or tone established by the teacher, and general culture, structure and order of the classroom as established by the teacher, as well as the students. While planning and teaching lessons is a challenge, creating both a safe and positive environment and still maintaining control of the classroom, is part of the daily task of a teacher. By the time GK-12 fellows had their first experience in the classroom as observers, these boundaries were well established, as teachers often try to set this dynamic as early in the school year as possible. There is a delicate balance for the teacher to be open, honest, and a caring person capable of mentoring or combating the many issues students bring with them to the classroom, and yet still maintain the role of the teacher, so that students feel safe and secure, and assured that they will be learning.

Secondary Theme: CEEEP - Teachers must show Compassion, Empathy, Encouragement, Energy and Patience.

There are a number of personal qualities and character traits and skills that a teacher should possess in order to relate to their students, for the students' emotional well-being. There is quite a wide range of positive and negative aspects of students' abilities, their assorted extracurricular activities, and home and social lives that each child comes enters the classroom with. Thus, it is not a surprise that GK-12 fellows saw their cooperating teachers demonstrate these qualities on a regular basis, and learned that these relational skills constructed a significant part of their teaching experience.

Fellow almost immediately recognize the importance of patience and remaining calm to promote an environment where students can learn, “...you have to be patient with students when they are struggling to understand certain concepts being taught to them...," and, "This week showed the great patience required to be a teacher...instead of reprimanding...she recognized that they were focused on studying their answers... her patience encourages them to continue asking questions."

Fellows began to realize that all student answers needed to be considered. Even when they may not have been correct, encouraging feedback was still given by the teacher, "At first I didn't realize I should support all the creative thinking and only focused on correct answers. But after watching (her) react to students' answers, I learned that encouragement should be taken."

Students who may be reluctant learners were also provided extra attention in order to motivate them to stay on task, "She took them aside and explained to them that even though it is difficult, the simulation is useful with learning..."

Fellows recognized that these traits possessed by their cooperating teachers were for all students, regardless their ability, background, or behavior, "She is always...positive and speaking encouraging words...," and, "The teacher provides...for all without discrimination and teaches according to the students' abilities."

Fellows learned that while pedagogy and lesson planning are time consuming portions of a teacher's daily routine, having the ability to connect and engage on a human level was a necessary part of the vocation as well, "(The teacher is) friendly to the students, cares about students' lives, and asks questions that foster student thinking."

\section{Secondary Theme: Classroom Management}

Classroom manager is one of several hats a teacher must wear. A distant or poor management style can impact the effect of teaching and learning that takes place. If a teacher does not provide leadership, that includes a clear set of rules and procedures, then students may resort to disorderly and disrespectful behavior, to the teacher and other classmates. The climate of the classroom becomes one where there is a battle between the teacher attempting to teach, and students unwilling or unable to learn. However, classroom management can be taught, with guidance and suggestions provided to incoming teachers. Through experience each teacher will eventually adopt their own individual style, through practice and experience. This code was the second-most cited $(0.83,167)$, giving credence to the fact that as fellows moved forward with the program, they realized that a well-managed classroom can be a place where effective teaching and true learning occur. GK-12 fellows observed a variety of these styles and outcomes, where leadership and getting and maintaining student attention was key, “...you have to be the leader of 
the classroom, and be able to get everyone's attention when needed," and, "I learned there are various ways of getting their attention: raising voice, being serious, mentioning something interesting topic..."

At times more immediate and direct action was necessary, "He was kindly asking them not to play games but finish their work... a few students who did not care... he had to unplug their computers...and warn them not to do it."

However, by careful observation and mimicking the actions of their cooperating teacher, the fellows were also able to be effective managers, "Since I've observed her reaction to bad behavior in the classroom, I was able to respond in the same way to get an effective response, making them stop."

Fellows noted that "with-it-ness" was an essential part of being a teacher, and that a sixth sense and having "eyes in the back of your head" was important for teachers to possess and for students to perceive, "...having situational awareness about what is happening in the space around you... is important."

\section{Secondary Theme: Relationships}

A teacher who can develop and maintain a positive relationship with students can create a classroom climate that is more conducive to learning. These relationships can produce more engaged, enthusiastic and productive students. Although fellows were in the classroom once a week, some students immediately gravitated toward these new additions to their class, and the fellows began bonding with their students as well, which also explains the high number of coded references in the journals $(0.73,140)$. "You have to spend time talking with students about topics not necessarily related to mathematics, such as responsibility...keep a good relationship with students, " and, "I was approachable...but extremely supportive...I was helpful...I finally think that the students are starting to open to me," and, "I try to be friendly and create an environment in which everybody can participate."

Having a good relationship with students can mitigate various issues that arise, by allowing the lesson to run more smoothly, "...the students even came to my help when I happened to be stuck with the Smartboard," and, "They are more likely to pay attention to a person they can relate to...they become interested...because someone they like is interested...rather than someone they are forced to sit and listen to..."

This positive energy that flows between the teacher and their students became apparent to the fellows as they observed and worked in the classroom, "I believe that is helps that he can understand where his students are coming from...he is...so engaging and absolutely loves his job...," and, "She communicates well with the students. She always showed interest on what they are talking about. They like to talk with her." This trait was one that fellows fostered to enhance their experience, as well as those of their students, "The students look up to you to be a role model and to guide them in what is acceptable behavior," and, “...it goes a long way when you try to be involved with the students as much as you can."

However, fellows were also able to recognize some negative relationships that many teachers had with their chosen career path. This negativity pervaded many aspects of the classroom culture. "She said she is too tired and overworked to try and connect with each student... she does not feel like she needs to help them if they are not willing to come to her for help...it may be (the teacher) is no longer putting in the effort," and, "She has the same attitude with me she has with her students: passive and really doesn't care...I cannot be like her or let myself become like her."

GK-12 fellows saw a number of ways that a healthy teacher-student relationship can be fostered, and the impact it has on the environment of the classroom. The quality of school life on both the teacher and the students, and in and out of the classroom, can be improved when the teacher takes the time and effort to maintain these connections. These associations can have an effect on the student far beyond the end of the school year.

\section{Conclusions and Implications}

Based on the research questions investigated, and the overarching goals of the sustained GK-12 program, the findings extracted from a qualitative analysis of the weekly reflections of the 60 former participants indicate that that they learned and employed a wide spectrum of skills that were necessary attributes a teacher must possess to be successful in the classroom. The first aspect is that fellows gained: an understanding of the pedagogical techniques and strategies to promote and improve student learning. This supports findings from Avery et al (2003), Huziak et al (2007), Thompson et al (2002) and Van Hook et al (2009). The other facets that emerged were the necessity to develop and possess a) the personality traits that promote learning and positive, well-managed and organized classroom culture, and b) the fortitude and resolve to rise to the many different challenges that can occur throughout the school day. These components are new findings not previously reported in the literature about the former NSF-funded program or more recent sustained programs. The richness and details of the observations and ideas 
expressed in the journals demonstrate that fellows learned, both explicitly and implicitly, about what was effective and what was not effective in teaching, and used this to reflect on their own teaching and learning experiences.

Despite diverse backgrounds, limited prior experience with teaching, and a relatively short program (ten days in the classroom), the sustained GK-12 program appears to have impacted the fellows in forming a new perspective on teaching and learning. Whether fellows came into the program looking to become future faculty members at universities or to become other types of professionals, participation in the program provided them with the realities and hands-on experience of the skills necessary to be a teacher of others. Based on the results of this study, we recommend that universities maintain and grow existing GK-12 programs, or consider initiating a self-supported GK-12 program to achieve broader outcomes for graduate education. By encouraging more graduate students from all disciplines to participate in such experiences, we contend that they will become more aware of many aspects of teaching and student learning, and its impact and purposefulness on making pedagogical and professional decisions. The next logical step is to survey and interview past participants of the GK-12 program in order to assess the continuing influence and impact the program has had on their career. This can also inform how to revise the program in its current state if there is an aspect of teaching and communicating with others that emerges during a professional career and not during their tenure as a GK-12 fellow.

Based on our experience, we recommend that training sessions early in the program emphasize through demonstration a wide assortment of teaching strategies to get students motivated to learn. GK-12 program instructors must also underscore to fellows that the educational system and mindset of fellows may be in stark contrast to the majority of students they typically encounter. For some children, learning may not be a priority, and they are in school because it is compulsory. Fellows must take this and the fact that these children are a full range of learning types and styles into consideration when developing their lessons. Fellows are constantly looking for guidance and feedback throughout the program on how they are progressing with their lesson. Initiating a weekly or bi-weekly feedback form to the cooperating teacher may also assist in helping fellows progress and improve their teaching and communication skills.

Our findings suggest indicate a noteworthy impact on fellows resulting from their GK-12 experience, but we do not yet know how this translates into the behavior of fellows when they become faculty or other types of professionals. We are presently conducting research to evaluate the retrospective views of GK-12 alumni on the program and investigate if what they perceive that they learned during their fellowship experience has changed since their participation. In future research, we recommend a longitudinal study of participants in their first few years as professionals, to investigate if aspects of their GK-12 experience were retained and how this impacted their behavior and progression in faculty and other professional positions.

\section{References}

Avery, L., Trautmann, N., \& Krasny, M. (2003). Impacts of Participation in a GK-12 Fellowship Program on teachers' conceptions and use of inquiry science. In 2003 National Association for Research in Science Teaching Annual Meeting, Philadelphia, Pennsylvania, March (pp. 22-26).

Cormas, P. C., \& Barufaldi, J. P. (2011). The effective research-based characteristics of professional development of the National Science Foundation's GK-12 program. Journal of Science Teacher Education, 22(3), 255-272. https://doi.org/10.1007/s10972-011-9228-1

Ferry, D. (2010). What do student teachers learn from their students? Set: Research Information for Teachers, (3), 46.

Huziak-Clark, T., Van Hook, S. J., Nurnberger-Haag, J., \& Ballone-Duran, L. (2007). Using Inquiry to Improve Pedagogy through K-12/University Partnerships. School Science and Mathematics, 107(8), 311-324. https://doi.org/10.1111/j.1949-8594.2007.tb17796.x

Laursen, S. L., Thiry, H., \& Liston, C. S. (2012). The Impact of a University-Based School Science Outreach Program on Graduate Student Participants' Career Paths and Professional Socialization. Journal of Higher Education Outreach and Engagement, 16(2), 47-78.

Lee, N., \& Reithmeier, R. (2013). The intention of graduate education.

McBride, B. B., Brewer, C. A., Bricker, M., \& Machura, M. (2011). Training the next generation of renaissance scientists: the GK-12 ecologists, educators, and schools program at the University of Montana. BioScience, 61(6), 466-476. https://doi.org/10.1525/bio.2011.61.6.9 
Mitchell, J., Levine, R., Gonzalez, R., Bitter, C., Webb, N., \& White, P. (2003). Evaluation of the National Science Foundation Graduate Teaching Fellows in K-12 Education Program.

National Science Foundation, National Center for Science and Engineering Statistics. (2015). Doctorate Recipients from U.S. Universities: 2014. Special Report NSF 16-300. Arlington, VA. Retrieved from http://www.nsf.gov/statistics/2016/nsf16300/

Page, M., Wilhelm, M. S., \& Regens, N. (2011). Preparing graduate students for teaching: Expected and unexpected outcomes from participation in a GK-12 classroom fellowship. Journal of College Science Teaching, 40(5), 32-37.

Thompson, S. L., Collins, A., Metzgar, V., Joeston, M. D., \& Shepherd, V. (2002). Exploring Graduate-Level Scientists' Participation in a Sustained K-12 Teaching Collaboration. School Science and Mathematics, 102(6), 254-265. https://doi.org/10.1111/j.1949-8594.2002.tb17884.x

Trautmann, N. M., \& Krasny, M. E. (2006). Integrating teaching and research: A new model for graduate education? BioScience, 56(2), 159-165. https://doi.org/10.1641/0006-3568(2006)056[0159:ITARAN]2.0.CO;2

Van Hook, S. J., Huziak-Clark, T. L., Nurnberger-Haag, J., \& Ballone-Duran, L. (2009). Developing an understanding of inquiry by teachers and graduate student scientists through a collaborative professional development program. Electronic Journal of Science Education, 13(2).

Weeks, F., \& Harbor, J. (2014). Assessing the impact of a K-12 engagement program on graduate learning outcomes for communicating with diverse audiences, pedagogy, and community engagement. International Journal for the Scholarship of Teaching and Learning, 8(2), 16. https://doi.org/10.20429/ijsotl.2014.080216

Weeks, F., Gong, R., \& Harbor, J. (2015). A Longitudinal Study of the Effectiveness of a K-12 Engagement Program on Graduate Student Learning Outcomes. International Journal of Higher Education, 4(3), p188. https://doi.org/10.5430/ijhe.v4n3p188

Wendler, C., Bridgeman, B., Markle, R., Cline, F., Bell, N., McAllister, P., \& Kent, J. (2012). Pathways through Graduate School and into Careers. Educational Testing Service. 